\title{
Adenocarcinoma pulmonar em um bovino
}

\author{
Pulmonary adenocarcinoma in a bovine
}

\begin{abstract}
Aline de Marco Viott ${ }^{\mathrm{I}}$ Ingeborg Maria Langohr ${ }^{\mathrm{II}}$ Fábio Augusto Vannucci ${ }^{\mathrm{I}}$ Aliny Pontes Almeida' ${ }^{\mathrm{I}}$ ômulo Cerqueira Leite ${ }^{\mathrm{III}}$ Roselene Ecco $^{\mathrm{I}^{*}}$
\end{abstract}

- NOTA-

\section{RESUMO}

Um bovino Guzerá, fêmea, adulto, com histórico de insuficiência cardíaca congestiva direita de duração de duas semanas, morreu durante o transporte ao hospital veterinário. À necropsia, o lobo pulmonar cranial esquerdo estava moderadamente aumentado de tamanho e firme. O parênquima do lobo afetado era branco e continha múltiplas áreas de 0,3 a 1,5cm de diâmetro, amareladas e caseosas. Alterações semelhantes foram observadas nos linfonodos mediastínicos e brônquicos, no pericárdio parietal, no epicárdio e na adventícia da artéria pulmonar. Histologicamente, a massa tecidual do lobo pulmonar era constituída por células epiteliais neoplásicas de padrão acinar, com duas ou mais camadas celulares, algumas com projeções papilares intraluminais. A anisocariose era acentuada, e o índice mitótico, moderado (dois a três por campo de maior aumento). Envolvendo as neoformações, observava-se abundante tecido conjuntivo fibroso. Focos de necrose e mineralização eram multifocais moderados. Alterações histológicas semelhantes foram observadas nos linfonodos brônquicos, nos mediastínicos, nos pericárdios visceral e parietal e na adventícia da artéria pulmonar. Com exceção do fígado com congestão generalizada crônica, não foram observadas alterações macro $e$ microscópicas em outros órgãos. Os achados histológicos foram compatíveis com adenocarcinoma pulmonar, com metástases regionais. O quadro de insuficiência cardíaca congestiva direita provavelmente foi decorrente do impedimento da drenagem linfática pelas metástases.

Palavras-chave: bovino, adenocarcinoma pulmonar, metástases, insuficiência cardíaca congestiva direita.

\section{ABSTRACT}

An adult Guzera cow, dysplaying for two weeks signs of right-sided congestive heart failure died during the transport to the veterinary hospital. At necropsy, the left cranial lung lobe was moderately increased in volume and firm. The parenchyma of the affected lung lobe was white and contained multiple 0.3 to $1.5 \mathrm{~cm}$ in diameter, yellow, dry, friable nodules. Similar changes were observed in bronchial and mediastinal lymph nodes, parietal pericardium, epicardium, and adventitia of the pulmonary artery. Microscopically, the pulmonary tissue mass was composed of neoplastic epithelial cells arranged in acini lined by two or more layers, some with intraluminal papillary projections. Anisokaryosis was marked, and mitotic index was moderate (2-3 mitosis in high field). Abundant fibrous connective tissue surrounded the neoplastic cell aggregates. Foci of necrosis and mineralization were moderate. Similar microscopic changes were observed in bronchial and mediastinal lymph nodes, visceral and parietal pericardium and adventitia of the pulmonary artery. With liver chronic generalized congestion exception, no other macro or microscopic lesions were observed. Microscopic findings were consistent with pulmonary adenocarcinoma with regional metastases. The right-sided congestive heart failure was probably due to obstruction of lymphatic drainage by metastases.

Key words: bovine, pulmonary adenocarcinoma, metastases, right congestive heart failure.

'Departamento de Clínica e Cirurgia Veterinária, Escola de Veterinária (EV), Universidade Federal de Minas Gerais (UFMG), 30193-970, Belo Horizonte, MG, Brasil. E-mail: ecco@vet.ufmg.br. *Autor para correspondência.

"Department of Pathobiology and Diagnostic Investigation, College of Veterinary Medicine, Michigan State University, East Lansing, MI, EUA.

IIIDepartamento de Medicina Veterinária e Preventiva, EV, UFMG, Belo Horizonte, MG, Brasil. 
Neoplasias pulmonares são raras em bovinos (MIGAKI et al., 1974). Em um estudo realizado em um abatedouro na Grã-Bretanha, foram encontrados 25 tumores primários de pulmão ao exame de 1 milhão e 300 mil bovinos (ANDERSON \& SANDISON, 1968). Dentre os neoplasmas pulmonares que já foram relatados nos bovinos, estão os blastomas pulmonares (KELLEY et al., 1994), o carcinoma de células pequenas e anaplásicas do pulmão (PIERCY et al., 1993) e os carcinomas bronquioloalveolares (OKADA et al., 1998). Entretanto, a maioria dos tumores pulmonares encontrados nos bovinos são adenocarcinomas. Esses tumores podem ser subdivididos em quatro padrões histológicos distintos: papilar, acinar, sólido e misto (MEUTEN, 2002), sendo os padrões papilar e acinar os mais frequentes nos animais domésticos (CASWELL \& WILLIAMS, 2007). Metástases de carcinomas pulmonares, quando presentes, ocorrem por invasão local e por via linfática ou hematógena (MEUTEN, 2002). Em razão da raridade de carcinomas pulmonares em bovinos, pouco é conhecido sobre o comportamento desses neoplasmas nesses animais. No Brasil, relatos de adenocarcinoma pulmonar primário em bovinos não foram encontrados. Os objetivos deste trabalho são relatar a ocorrência e descrever os aspectos macroscópicos e histológicos de um adenocarcinoma pulmonar com mestástase intratorácica em um bovino.

Um bovino Guzerá, fêmea, adulto, com histórico de insuficiência cardíaca congestiva direita de duração de duas semanas, desenvolveu sinais de cansaço e aumento de volume na região submandibular, cervical e esternal durante dois meses. Clinicamente, apresentava dispneia, pulso jugular positivo e som abafado na auscultação cardíaca. Durante o transporte para o Hospital Veterinário da Universidade Federal de Minas Gerais, o animal morreu e foi encaminhado para o setor de patologia. À necropsia, o cadáver apresentava bom estado nutricional. Havia edema subcutâneo intenso na região ventral do pescoço e do esterno. A cavidade torácica continha 20L de transudato (Figura 1A). O lobo pulmonar cranial esquerdo estava moderadamente aumentado de volume e firme e era moteado por áreas brancas e vermelho-escuras. Ao corte, essas áreas continham múltiplos focos amarelados, secos, caseosos e friáveis, de 0,3 a $1,5 \mathrm{~cm}$ de diâmetro (Figura 1B). Os linfonodos mediastínicos e brônquicos estavam intensamente aumentados de volume e ao corte apresentavam perda de distinção entre cortical e medular, coloração esbranquiçada e continham focos amarelados semelhantes aos observados no pulmão (Figura 1C), e alguns desses apresentavam aspecto caseoso e mineralizado ao corte.
O saco pericárdico estava acentuadamente distendido por oito litros de líquido avermelhado e levemente viscoso. O pericárdio parietal continha nodulações multifocais firmes, branco-amareladas, de 0,1 a 0,3cm de diâmetro (Figura 1D). Lesões multifocais a coalescentes semelhantes às descritas eram frequentes também no epicárdio e na adventícia da artéria pulmonar. Havia ainda hidroperitôneo intenso, com aproximadamente 30L de transudato. $\mathrm{O}$ fígado estava acentuadamente aumentado de volume, com bordos arredondados e superfície subcapsular azulada. O parênquima hepático estava moderadamente firme e com aspecto típico de "noz-moscada”. Amostras teciduais foram coletadas, fixadas em formol tamponado a $10 \%$ e processadas rotineiramente para histopatologia.

Histologicamente, o pulmão continha áreas de necrose caseosa e mineralização distrófica envoltas por células neoplásicas epiteliais pleomórficas e infiltrativas. O citoplasma dessas células era abundante, e os núcleos eram centrais, redondos, com anisocariose acentuada e nucléolos evidentes. O índice mitótico era moderado (dois a três por campo de maior aumento). As células estavam arranjadas em ácinos constituídos por duas ou mais camadas epiteliais, alguns com projeções papilares intraluminais. Envolvendo essas áreas, observava-se abundante tecido conjuntivo fibroso em feixes ou em arranjo circular (Figura 1E). Na lâmina própria dos brônquios, havia arranjos acinares pleomórficos semelhantes. Além disso, observaram-se focos de necrose cercados por infiltrado inflamatório mononuclear composto por alguns macrófagos e células gigantes multinucleadas. Os linfonodos mediastínicos e bronquiais (Figura 1F), os nódulos presentes na adventícia da artéria pulmonar e os pericárdios parietal e visceral tinham alterações neoplásicas similares às descritas no pulmão, caracterizando metástases. Nos linfonodos, a proliferação neoplásica ocupava quase todo o parênquima, com extensas áreas de necrose caseosa e mineralização. No fígado, havia acentuada congestão dos sinusoides, com perda de hepatócitos e fibroplasia centro-lobular (fígado cardíaco). Não foram observadas alterações macro e microscópicas em outros órgãos.

Os achados patológicos nesse bovino foram consistentes com adenocarcinoma pulmonar primário, com metástases para os linfonodos regionais, adventícia, saco pericárdico e epicárdio. Os adenocarcinomas pulmonares abrangem tumores de histogênese variável compostos unicamente ou por uma mistura de estruturas glandulares, mistas, acinares, papilares ou sólidas. São derivados das células alveolares, das glândulas bronquiais ou do epitélio dos 


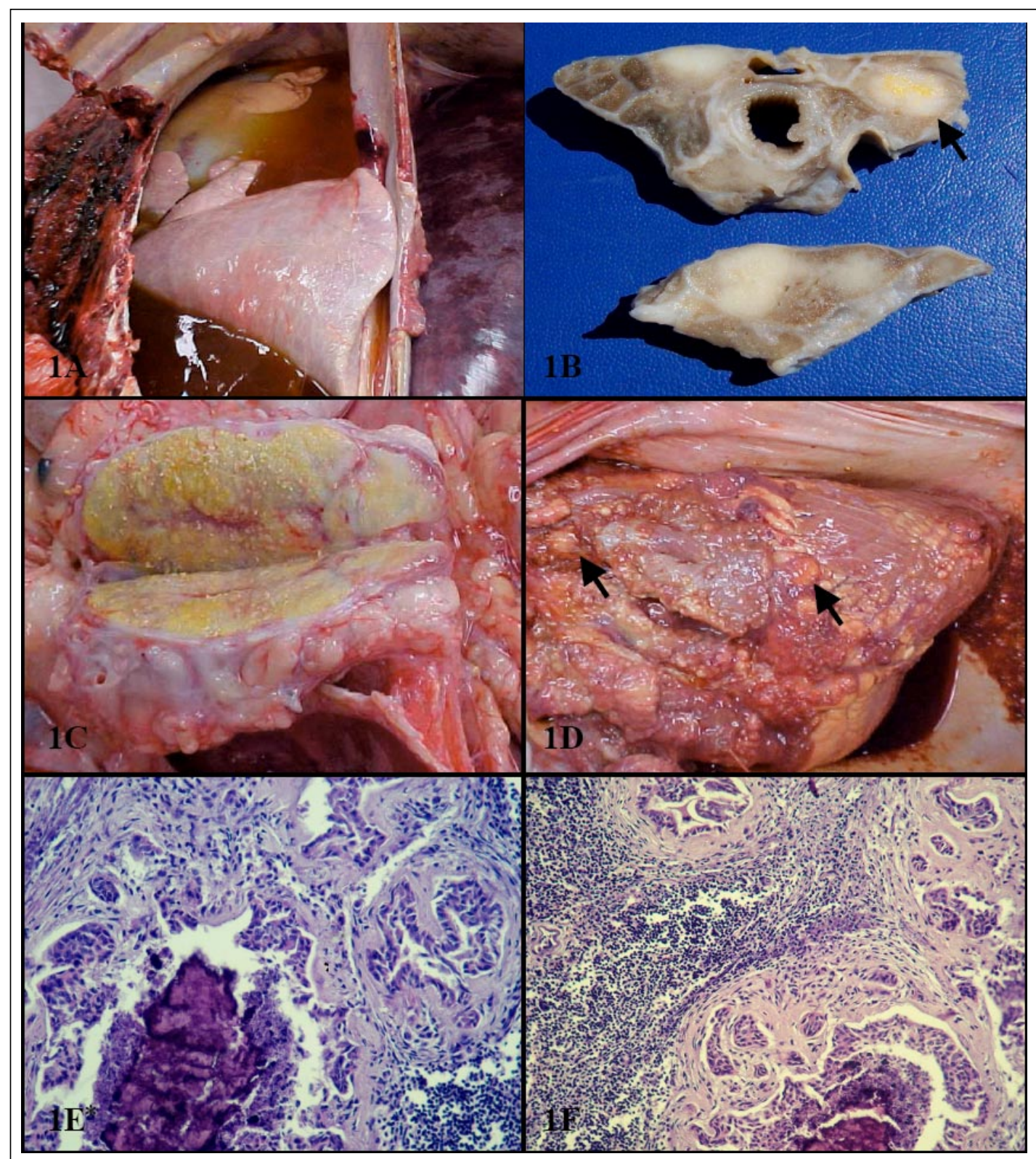

Figura 1 - Adenocarcinoma pulmonar, bovino. 1A) Cavidade torácica com aproximadamente 20L de transudato amarelo citrino. 1B) Superfície de corte do pulmão, fixado em formol, apresentando nódulos brancos e firmes. Na região central (seta) de um dos nódulos observa-se área amarelada e seca (mineralização). 1C) Metástase de adenocarcinoma pulmonar. Linfonodo mediastínico aumentado de volume. Ao corte observamse múltiplos nódulos amarelados e friáveis. 1D) Metástase de adenocarcinoma pulmonar. Pericárdio visceral e parietal apresentando pequenas nodulações (setas) brancas e firmes ou amareladas e secas. 1E) Pulmão. Proliferação celular neoplásica constituída de células epiteliais pleomórficas infiltrativas arranjadas em ácinos envoltos por fibrose (*). Centralmente há necrose e mineralização distrófica. H.E. 40x. 1F) Mestástase de adenocarcinoma pulmonar. Linfonodo infiltrado por células neoplásicas arranjadas em ácinos envoltas por abundante tecido conjuntivo fibroso. H.E. 20x.

bronquíolos (MEUTEN, 2002). A histogênese pulmonar desse tumor não foi claramente definida. Em uma das áreas do tumor, havia formações neoplásicas acinares ao redor dos brônquios, sugerindo uma possível origem das glândulas bronquiais.
A neoplasia foi diferenciada de mesotelioma epiteiloide em razão da presença de núcleos basais e uniformes das células que formavam os ácinos, característica ausente nos mesoteliomas que possuem células granulares com núcleos irregulares e ácinos 
primitivos. Além disso, a ocorrência de metástases linfáticas nos mesoteliomas raramente é citada (MEUTEN, 2002). Adenocarcinomas pulmonares com característica esquirrosa, em bovinos, devem ser diferenciados de outros neoplasmas epiteliais, principalmente neoplasmas primários de útero e pâncreas (MEUTEN, 2002). No entanto, a ausência de qualquer alteração nesses órgãos descartou essa possibilidade.

Os sinais clínicos desse bovino indicavam doença cardiovascular, possivelmente endocardite valvular direita ou pericardite traumática. À necropsia, o aspecto caseo-calcário dos linfonodos e dos nódulos no pericárdio parietal e epicárdio sugeriu tuberculose. Entretanto, as alterações histológicas foram consistentes com neoplasma primário de pulmão. Apesar de nódulos desse tipo de tumor serem geralmente sólidos, muitos têm áreas centrais de necrose lembrando macroscopicamente granulomas (CASWELL \& WILLIAMS, 2007). Em humanos, há relatos de infecção por Mycobacterium sp. associado com adenocarcinoma pulmonar (KOBASHI et al. 2004, SAWAI et al. 2008). No presente caso, secções histológicas foram submetidas à coloração pelo ZiehlNeelsen com resultado negativo.

A insuficiência cardíaca direita foi considerada a causa mais provável da morte do animal. Nesta, o agravamento dos sinais clínicos e a morte são desencadeados quando o animal é submetido a algum esforço físico ou estresse, nesse caso, quando o animal foi transportado. A insuficiência cardíaca deve ter ocorrido pelo acúmulo progressivo de fluído no espaço pericárdico. Isso pode ter sido ocasionado pela diminuição da drenagem linfática da região comprometida pelo crescimento tumoral metastático ou irritação das superfícies serosas envolvidas, levando à secreção excessiva de líquido ou ambos. O fluído acumulado deve, por fim, ter interferido no retorno venoso para o átrio e ventrículo direito do coração.

O padrão morfológico das células neoplásicas permitiu classificar o tumor como adenocarcinoma acinar pulmonar. Tumores pulmonares primários com metástases para linfonodos regionais e epicárdio são raros em bovinos e podem determinar quadros de insuficiência cardíaca congestiva nesses animais.

\section{REFERÊNCIAS}

ANDERSON, L.J.; SANDISON, A.T. Pulmonary tumors found in a British Abattoir survey: Primary carcinomas in cattle and secondary neoplasms in cattle, sheep and pigs. British Journal Cancer, v.22, p.47-57, 1968.

CASWELL, J.L.; WILLIAMS, K.J. Respiratory tract. In: JUBB, K.V.F. et al. Pathology of domestic animals. New York : Saunders, 2007. V.2, cap.2, p.550-551.

KELLEY, L.C. et al. Bovine pulmonary blastomas: histomorphologic description and immunohistochemistry. Veterinary Pathology, v.31, p.658-662, 1994.

KOBASHI, Y. et al. Pulmonary Mycobacterium avium disease with a solitary pulmonary nodule requiring differentiation from recurrence of pulmonary adenocarcinoma. Internal Medicine, v.43, n.9, p. 855-859, 2004. Disponível em: <http://dx.doi.org/ doi: 10.2169/internalmedicine.43.855>. Acesso em: 19ago.2009. doi: 10.2169/internalmedicine.43.855.

MEUTEN, D.J. Tumors in domestic animals. Iowa: Iowa state, 2002. Cap.7, p.365-399.

MIGAKI, G. et al. Primary pulmonary tumors of epithelial origin in cattle. Journal of the American Veterinary Medical Association, v.35, n. 11, p.1397-1400, 1974.

OKADA, Y. et al. Bronchiolar-alveolar carcinoma in a cow. Journal Comparative Pathology, v.118, p.69-74, 1998.

PIERCY, D.W.T. et al. Anaplastic small cell carcinoma of the lung in a six-month-old Friesian calf. Veterinary Record, v.132, p.386-387, 1993.

SAWAI, T. et al. Mycobacterium intracellulare pulmonary infection which co-existed and mimicked lung cancer. Internal Medicine, v.47, p.459-462, 2008. Disponível em: <http:// dx.doi.org/ doi:10.2169/internalmedicine.47.0586>. Acesso em: 17ago. 2009. doi: doi:10.2169/internalmedicine.47.0586. 